RESEARCH ARTICLE

\title{
Effect of Slice Thickness, Boiling and Drying Methods on Curcumin, Oleoresin and Essential Oil Content of Ground Turmeric
}

\author{
Nithya $\mathbf{C}^{* 1}$, Thangavel $\mathbf{K}^{1}$, Amirtham $\mathbf{D}^{1}$, Indu Rani $\mathbf{C}^{2}$ and Pandiarajan $\mathrm{T}^{3}$ \\ ${ }^{* 1}$ Department of Food and Agricultural Process Engineering, AEC\&RI, TNAU, Coimbatore - 641003. \\ ${ }^{2}$ Department Floriculture and Landscape Architecture, ADAC\&RI, TNAU, Trichy - 620027. \\ ${ }^{3}$ Department of Food Agricultural Process Engineering and Basic Sciences, AEC\&RI, TNAU, Kumulur - 621712.
}

Received : $08^{\text {th }}$ January, 2020

Revised : $05^{\text {th }}$ February, 2020

Revised : $12^{\text {th }}$ February, 2020

Accepted : $18^{\text {th }}$ February, 2020

\begin{abstract}
A study was carried out to analyze the effect of slicing, boiling, and drying methods on the extraction of curcumin, oleoresin, and essential oil content of ground turmeric. The factors and their levels selected for the study were slice thickness of $2 \mathrm{~mm}$ and $3 \mathrm{~mm}$, boiling methods such as pressure boiling at $0.25,0.5,0.75$ and $1 \mathrm{kgcm}^{-2}$. Drying methods including tray drying, microwave drying, and vacuum drying were also evaluated. A three factorial completely randomized design was used to study the effect of slice thickness, boiling, and drying methods on curcumin content, oleoresin content, essential oil content of ground turmeric. Water boiled and sun-dried whole rhizomes were kept as the control for the study. CO2 variety of turmeric was used for the study. Highest curcumin content (4.35\%) was obtained from $2 \mathrm{~mm}$ thick, unboiled, and vacuum dried slices, and the lowest curcumin content (2.34\%) was recorded from $3 \mathrm{~mm}$ thick, $1 \mathrm{kgcm}^{-2}$ pressure boiled and microwave dried samples. The highest oleoresin content $(8.86 \%)$ was recorded by unboiled, vacuum dried samples while lowest (7.13\%) oleoresin content was shown by $1 \mathrm{kgcm}^{-2}$ pressure boiled and tray dried samples. The study revealed that unboiled turmeric showed better quality than water boiled and pressure boiled turmeric with respect to the curcumin, oleoresin, essential oil content. During pressure boiling, the quality got reduced with an increase in pressure. Mechanical drying methods provided better quality turmeric than sun-dried turmeric. Vacuum drying yielded superior quality turmeric than other mechanical drying methods.
\end{abstract}

Keywords: Tray, microwave, vacuum, curcumin, oleoresin, essential oil.

\section{INTRODUCTION}

Turmeric, 'the golden spice of life', is one of the major spice crops in India. India is the major producer, consumer, and exporter of turmeric in the world. During 2015-2016, India produced 9,67,060 tonnes of turmeric and exported 88,500 tonnes valued at Rs.92,165 lakhs. Telangana was the major turmeric producing state in India during 2015-2016, which had a cultivated area of 42540 ha with 1,84290 tonnes of turmeric production (Statistics., 2015).

Turmeric processing involves cleaning, washing, boiling, drying, polishing, grading and packaging. Curing or boiling of fresh rhizomes promotes the gelatinization of starch, facilitates uniform drying, and increases the drying rate (Govindarajan and Stahl, 1980). On the other hand, unblanched samples were found to be superior in quality than blanched samples. (Pradeep et al., 2016; Prasad et al., 2006). Hence, there is no conclusive result in the literature about the effect of boiling on the quality of the turmeric. There is a need for more research studies related to the effect of boiling on the quality of turmeric.

Turmeric is traditionally processed by boiling in water along with cow dung slurry or boiling in alkaline water, followed by drying under the sun. But the traditional method has numerous disadvantages. It is a very time consuming and less energy-efficient process. Sometimes the rhizomes under the bottom are overcooked and at the top are undercooked. Such improper cooking makes the product brittle (Patil and Chhapkhane, 2013; Shinde et al., 2011).

Steam boiling is the most suitable alternative to traditional water boiling and is widely accepted by farmers. Steam boiling can be performed by open steam boiling or pressure boiling. During pressure boiling, water vapour doesn't escape to the atmosphere, and the uniform distribution of steam occurs inside the vessel. Hence, pressure boiling is more time and energyefficient than open steam boiling (Shinde et al., 2011). 
Drying rhizomes as a whole is a time-consuming process. Borah et al. (2015) found that drying time could be reduced by slicing from their study on drying kinetics of whole and sliced turmeric rhizomes in a solar conduction dryer. Traditional sun-drying takes about 10-15 days for drying, and it is highly weather dependent. The non-uniform heating and longer drying time adversely affect the quality of turmeric by causing some chemical changes like browning (Bambirra et al., 2002). Mechanical drying addresses almost all the drawbacks of sun drying. Hot air drying is the most common method for drying of food materials. But it also causes various quality losses such as the reduction in colour, taste, and nutrient content in the dried product. Microwave and vacuum drying are two innovative drying methods that overcome several drawbacks of sun drying and hot air drying. High energy efficiency, uniform heating, less drying time, improved quality of dried products are the major advantages of microwave drying. Vacuum drying is a potential drying technique for heat sensitive products which take place at low temperature and pressure in reduced oxygen environment.Considering the above facts, the present study was undertaken to analyze the effect of different boiling, slicing, and drying methods on quality characteristics of ground turmeric.

\section{MATERIAL AND METHODS}

\section{Turmeric boiling and slicing}

Fresh turmeric rhizomes of $\mathrm{CO} 2$ variety immediately after harvest were purchased from M/S GS farms, Kalipalayam, Coimbatore. Traditional water boiling was performed in a vessel with water just enough to soak the rhizomes. Boiling was stopped when froth came out, with the release of white fumes having a typical turmeric aroma. Pressure boiling was performed in the laboratory autoclave. One kg of turmeric rhizomes after washing were placed inside the autoclave, and steaming was carried out at $0.25 \mathrm{~kg} . \mathrm{cm}^{-2}$ for $5 \mathrm{~min}$. After steaming, the turmeric rhizomes were divided into two halves. One-half of rhizomes were cut into $2 \mathrm{~mm}$ thick and another half into $3 \mathrm{~mm}$ thick. The steaming and slicing were repeated at 0.5, 0.75, and $1 \mathrm{~kg} . \mathrm{cm}^{-2}$ and $2 \mathrm{~mm}$ and $3 \mathrm{~mm}$ respectively. The sliced turmeric was dried in tray drier, microwave drier, and vacuum drier. The treated rhizomes were sliced using a thickness adjustable vegetable slicer, and the thickness was measured using a Vernier caliper.

\section{Drying}

Water boiled whole rhizomes were spread on a plain plastic sheet and subjected to sun drying from 8.00 am to $4.00 \mathrm{pm}$ in a day. Tray drying of raw and boiled turmeric slices was performed in a tray drier at a temperature of $60^{\circ} \mathrm{C}$. Drying was performed until the moisture content reached below $10 \%$, and the slices break with a metallic sound. Microwave drying was performed in a microwave oven(IFB $235 C 1$ model) of 800 W output capacity with provisions to adjust power level and time. 250 g of sliced rhizomes were kept over a circular glass plate inside the drying chamber.

A preliminary study was carried out at 40,50 , and $60 \%$ power levels to optimize the power level. Based on colour value and results by Assawarachan et al. (2013), the power level was fixed as $50 \%$ (400-W) and time as 5 min for the operation of the microwave oven. Preliminary trials of vacuum drying were performed in the vacuum dryer at 40,50, and $60^{\circ} \mathrm{C}$ in order to find the optimum temperature. The temperature was optimized as $60^{\circ} \mathrm{C}$ based on the high colour value and drying rate obtained. Drying of samples was carried out at $60^{\circ} \mathrm{C}$ and $760 \mathrm{~mm}$ $\mathrm{Hg}$ vacuum (6.9 $\mathrm{kPa})$. Dried turmeric slices were packed in 42 microns thick, small size $(21.3 \mathrm{~cm} \times$ $18 \mathrm{~cm}$ ) fresh-n-loc Zipouches (Uflex Limited, Noida).

\section{Quality Evaluation}

\section{Curcumin}

Curcumin content was determined as per the procedure followed by IS - 10925: 1984.

Curcumin content was estimated by the following formula,

$$
\begin{aligned}
& \text { Curcumin } \\
& \text { content } \%=\frac{\begin{array}{c}
0.0025 \times \mathrm{A}_{425} \times \text { Volume } \\
\text { made up } \times \text { Dilution factor }
\end{array}}{0.42 \times \text { Weight of the sample }} \times 100---(1) \\
& \text { Oleoresin }
\end{aligned}
$$

Oleoresin content was determined as per IS Specification no IS 1797- 1985.

Percentage of oleoresin was estimated using the formula, Weight of concentrate

$$
\begin{gathered}
\text { Oleoresin \% }=\frac{\text { obtained after evoporation }}{\text { Mass in gram of the }} \times 100---(2) \\
\text { sample }
\end{gathered}
$$

The essential oil was separated by steam distillation using a Clevenger apparatus. The ground turmeric was distilled with water and the oil was carried over with the steam and condensed with it. The oil and water were separated into distinct layers based on the density difference.

Percentage of oil recovered was estimated using

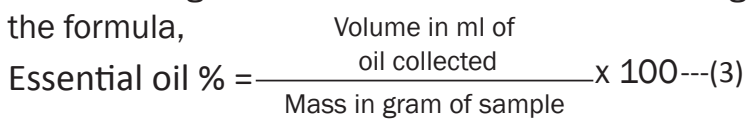

\section{Statistical}

Design

The data from curcumin, oleoresin, essential oil were statistically analyzed using AGRES software $107|1-3| 89$ 
(Version 3.01). The data were subjected to Analysis of variance (ANOVA) with the mean comparison performed using three factorial completely randomized factorial design.

\section{RESULTS AND DISCUSSION}

From the analysis of biochemical quality of turmeric rhizomes, it was found that the water boiled and sun-dried whole rhizomes contained an average curcumin content of $3.31 \%$. The average oleoresin and essential oil content of the control sample were found to be $6.37 \%$ and $2.33 \%$, respectively.

\section{Effect of slicing, boiling and drying methods on quality characteristics}

\section{Curcumin}

The effect of slice thickness, boiling methods, and drying methods on curcumin content is shown in Figure 1a. The analysis of variance indicated that all the factors and their combinations had a significant effect $(P<0.05)$ on curcumin content. It was observed that un-boiled, $2 \mathrm{~mm}$ thick, vacuum dried samples showed the highest curcumin content of $4.35 \% .2 \mathrm{~mm}$ samples took less time to dry than

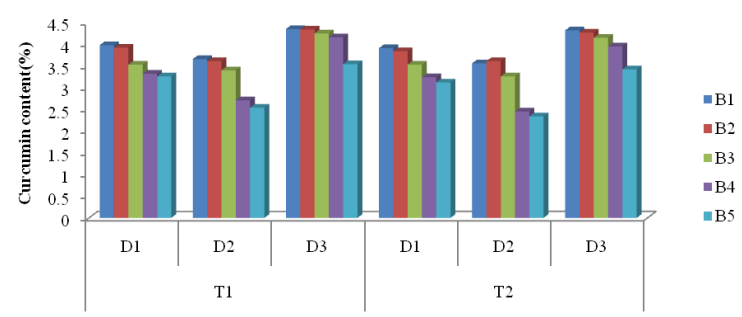

Figure 1a. Effect of slicing, boiling and drying methods on curcumin content

T1- $2 \mathrm{~mm}$ slice thickness T2 $-3 \mathrm{~mm}$ slice thickness

D1- Tray drying D2- Microwave drying D3- Vacuum drying

B1- Without boiling B2- $0.25 \mathrm{~kg} . \mathrm{cm}^{-2}$ B3- $0.5 \mathrm{~kg} . \mathrm{cm}^{-2}$ B4- $0.75 \mathrm{~kg} . \mathrm{cm}^{-2}$ B5- $1 \mathrm{~kg} . \mathrm{cm}^{-2}$

$3 \mathrm{~mm}$ samples since the distance traveled by moisture to the surface is less at lower thickness. $2 \mathrm{~mm}$ thick samples showed a significantly $(P<0.01)$ higher curcumin content than $3 \mathrm{~mm}$ samples. Deterioration of curcumin content at a higher temperature and longer drying time was observed by Saetan et al. (2013).

Unboiled rhizomes showed a higher curcumin content than pressure boiled rhizomes. This result was in accordance with the results of Sampathu et al. (1988), who found that better recovery of curcumin was found in uncooked slices compared to cooked rhizomes. Pradeep et al. (2016) also reported that curcumin content was higher in unblanched turmeric slices under mechanical drying. During pressure boiling curcumin content showed a decreasing trend with an increase in pressure. Srinivasan et al. (1992) also reported that the maximum loss of curcumin was observed in pressure cooking. The curcumin content was higher at $0.25 \mathrm{~kg} . \mathrm{cm}^{-2}$ and when pressure level increased, the content got reduced. This might be due to the evaporation of curcumin at high pressure and temperature (Athmaselvi and Varadharaju, 2002).

Vacuum dried slices showed a higher curcumin content followed by tray dried and then microwave dried samples. Since vacuum drying takes place at low pressure, water boils, and evaporates at a lower temperature, and hence the quality of the product is preserved (Laopoolkit and Suwannaporn, 2011).

\section{Oleoresin}

Figure $1 \mathrm{~b}$ shows the effect of slicing, boiling, and drying methods on Oleoresin content. All the treatments and treatment combinations had a significant effect on oleoresin content $(P<0.01)$. $2 \mathrm{~mm}$ thick samples showed a slight increase in oleoresin content compared to $3 \mathrm{~mm}$ samples. Vacuum dried samples showed significantly higher $(\mathrm{P}<0.01)$ oleoresin content of $8.4 \%$ while tray dried and microwave dried samples showed comparatively lower and similar oleoresin content of 7.86 and $7.88 \%$ respectively. Oleoresin content significantly reduced $(P<0.01)$ with an increase in pressure during pressure boiling. Un-boiled samples showed the highest oleoresin content of $8.59 \%$, whereas those treated at $1 \mathrm{~kg} . \mathrm{cm}^{-2}$ showed the lowest

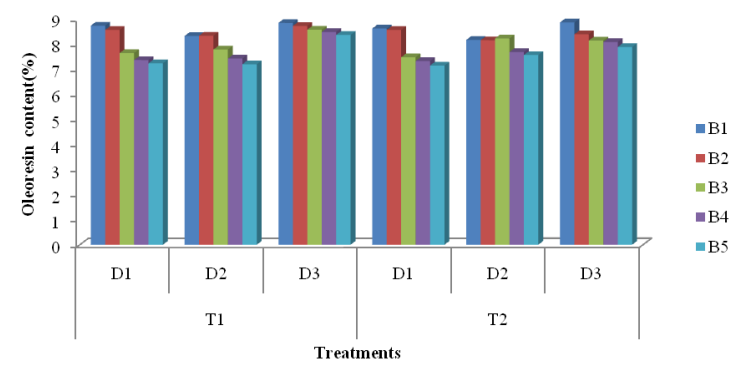

Figure 1b. Effect of slicing, boiling and drying methods on oleoresin content

T1- $2 \mathrm{~mm}$ slice thickness T2 - $3 \mathrm{~mm}$ slice thickness

D1- Tray drying D2- Microwave drying D3- Vacuum drying

B1- Without boiling B2- $0.25 \mathrm{~kg} . \mathrm{cm}^{-2}$ B3- $0.5 \mathrm{~kg} . \mathrm{cm}^{-2}$ B $4-0.75 \mathrm{~kg} . \mathrm{cm}^{-2}$ B5- $1 \mathrm{~kg} . \mathrm{cm}^{-2}$

oleoresin content of $7.56 \%$. This result was in accordance with the results of Athmaselvi and Varadharaju.(2002), who reported that during pressure boiling Curcumin, oleoresin, and essential oil content decreased with an increase in pressure. While considering the effect of three factors at a time, 2 and $3 \mathrm{~mm}$ thick, un-boiled vacuum dried samples and $2 \mathrm{~mm}$ thick un-boiled and tray dried samples showed the highly significant $(P<0.01)$ oleoresin content. The lowest oleoresin content was recorded by tray dried and microwave dried samples boiled at $1 \mathrm{~kg} \cdot \mathrm{cm}^{-2}$. 


\section{Essential oil}

The effect of slicing, boiling, and drying methods on essential oil content is shown in Figure 1c. The essential oil content of $\mathrm{CO} 2$ variety under different slice thickness, boiling methods, and drying methods varied from $2 \%$ to $3.8 \%$. Vacuum dried samples yielded a significantly higher $(P<0.05)$ essential oil content of $3.1 \%$ than tray dried and microwave dried samples. The tray dried and microwave dried samples yielded an equal amount of oil, such as $2.78 \%$ and $2.73 \%$, respectively. Un-boiled samples (B1) recorded significantly higher oil content of 3.33\% than pressure boiled samples. Among pressure boiled samples, those boiled at $1 \mathrm{~kg} . \mathrm{cm}^{-2}$ recorded the lowest oil content of $2.25 \%$.

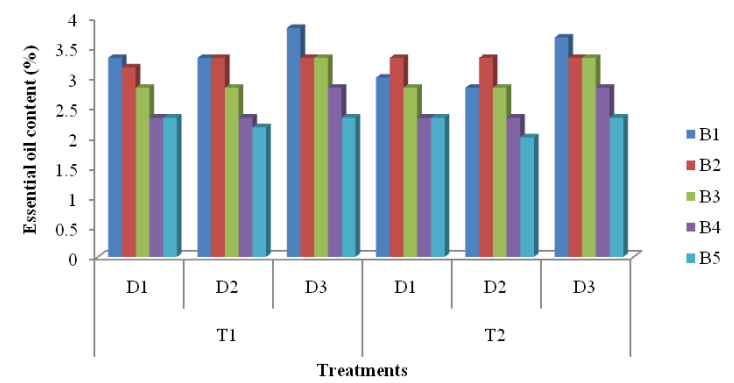

Figure 1c. Effect of slicing, boiling and drying methods on essential oil content

T1- $2 \mathrm{~mm}$ slice thickness T2 $-3 \mathrm{~mm}$ slice thickness D1- Tray drying D2- Microwave drying D3- Vacuum drying B1- Without boiling B2- $0.25 \mathrm{~kg} . \mathrm{cm}^{-2}$ B3- $0.5 \mathrm{~kg} . \mathrm{cm}^{-2}$ B4- $0.75 \mathrm{~kg} . \mathrm{cm}^{-2}$ B5- $1 \mathrm{~kg} . \mathrm{cm}^{-2}$

Similar results were reported by Athmaselvi and Varadharaju. (2002).

\section{CONCLUSION}

The slice thickness, boiling, and drying methods used in the study showed a significant effect on all the quality characteristics of ground turmeric. Control samples showed an average curcumin content of $3.31 \%$, oleoresin content of $6.37 \%$, essential oil content of $2.33 \%$. Highest Curcumin content $(4.35 \%)$ was obtained from un-boiled and vacuum dried slices, and the lowest Curcumin content $(2.34 \%)$ was recorded from $3 \mathrm{~mm}$ thick, $1 \mathrm{~kg} . \mathrm{cm}^{-2}$ pressure boiled and microwave dried samples. The highest oleoresin content (8.86\%) was recorded by un-boiled, vacuum dried samples while lowest (7.13\%) oleoresin content was shown by $1 \mathrm{~kg} . \mathrm{cm}^{-2}$ pressure boiled and tray dried samples. A more significant amount of essential oil was obtained from un-boiled as well as low pressure $\left(0.25 \mathrm{~kg} . \mathrm{cm}^{-2}\right)$ boiled samples under vacuum drying.

\section{REFERENCES}

Assawarachan, R., Kalayanamitra, K. and T.Keokamnerd. 2013. Modeling and Optimization of Microwave
Drying of Turmeric Slices. Paper presented at the II Southeast Asia Symposium on Quality Management in Postharvest Systems 1088.

Athmaselvi, K.A. and N. Varadharaju. 2002. Heat utilization in different methods of turmeric boiling. Madras. Agric. J. 90(4-6): 332-335.

Bambirra, M. L. A., Junqueira, R.G. and M.B.A.Glória. 2002. Influence of post harvest processing conditions on yield and quality of ground turmeric (Curcuma longa L.). Brazilian Archives of Biology and Technology. 45(4): 423-429.

Borah, A., Hazarika, K., and S. Khayer. 2015. Drying kinetics of whole and sliced turmeric rhizomes (Curcuma longa L.) in a solar conduction dryer. Information Processing in Agriculture. 2(2): 85-92.

Govindarajan, V. and W.H. Stahl. 1980. Turmericchemistry, technology, and quality. Critical Reviews in Food Science \& Nutrition. 12(3): 199-301.

IS 1797: 1985. Methods of test for spices and condiments. Bureau of Indian Standards (BIS).

IS 10925:1984. Specification for turmeric oleoresin. Bureau of Indian Standards (BIS).

Laopoolkit, P. and P.Suwannaporn. 2011. Effect of pretreatments and vacuum drying on instant dried pork process optimization. Meat science. 88(3): 553-558.

Patil, P.M. and N.K.Chhapkhane. 2013. Improving design and operation of steam based turmeric cooking process. International Journal of Engineering Research and Applications. 3(4): 933-935.

Pradeep, K., Ravi, R., Prakash, J.and M. Madhava Naidu. 2016. Influence of blanching and drying methods on the quality characteristics of fresh turmeric rhizomes. International Journal of Applied and Pure Science and Agriculture.2(3): 32-44

Prasad, J., Vijay, V., Tiwari, G.and V. Sorayan. 2006. Study on performance evaluation of hybrid drier for turmeric (Curcuma longa L.) drying at village scale. Journal of Food Engineering.75(4): 497-502.

Saetan, P., Pratinthong, N.and T. Swasdisevi. 2013. Turmeric drying using a combined vacuum and farinfrared dryer. Paper presented at the sixth TSAE International conference.

Sampathu, S., Krishnamurthy, N., Sowbhagya, H.and M.Shankaranarayana.1988. Studies on quality of turmeric (Curcuma longa) in relation to curing methods. Journal of Food Science and Technology. 25(3): 152-155.

Shinde, G.U., Kamble, K.J., Harkari, M.G.and G. More. 2011. Process optimization in turmeric heat treatment by design and fabrication of blancher. Paper presented at the International Conference on Environmental and Agriculture Engineering.

Srinivasan, K., Sambaiah, K. and N. Chandrasekhara.1992. Loss of active principles of common spices during domestic cooking. Food Chemistry. 43(4): 271-274.

Statistics.2015. Retrieved from http://www.indian spices. com/statistics. 